\title{
Deep Brain Stimulation: Expanding Applications
}

\author{
Anand TEKRIWAL ${ }^{1,2}$ and Gordon BALTUCH ${ }^{1}$ \\ ${ }^{1}$ University of Pennsylvania, Department of Neurosurgery, Philadelphia, USA; \\ ${ }^{2}$ University of Colorado School of Medicine and Graduate School of Neuroscience, \\ MSTP, Colorado, USA (current affiliation)
}

\begin{abstract}
For over two decades, deep brain stimulation (DBS) has shown significant efficacy in treatment for refractory cases of dyskinesia, specifically in cases of Parkinson's disease and dystonia. DBS offers potential alleviation from symptoms through a well-tolerated procedure that allows personalized modulation of targeted neuroanatomical regions and related circuitries. For clinicians contending with how to provide patients with meaningful alleviation from often debilitating intractable disorders, DBSs titratability and reversibility make it an attractive treatment option for indications ranging from traumatic brain injury to progressive epileptic supra-synchrony. The expansion of our collective knowledge of pathologic brain circuitries, as well as advances in imaging capabilities, electrophysiology techniques, and material sciences have contributed to the expanding application of DBS. This review will examine the potential efficacy of DBS for neurologic and psychiatric disorders currently under clinical investigation and will summarize findings from recent animal models.
\end{abstract}

Key words: neurosurgery, deep brain stimulation, Parkinson's disease, epilepsy, neuromodulation

\section{Introduction}

Deep brain stimulation (DBS) is acknowledged to be effective at modulating dysfunctional neural circuits that can be either hypo or hyperactive as seen in Parkinson's disease (PD) and dystonia, respectively. This treatment necessitates the placement of imageguided electrode that leads into discrete regions of patients' neuroanatomy. This is followed by titration of current through the leads, allowing for refinement of stimulatory parameters; please refer to previously published works for reference regarding implantation methodology. ${ }^{1-7)}$ The Food and Drug Administration (FDA) first approved thalamic DBS in 1997 for tremor, and globus pallidus internus (GPi) as well as subthalamic nucleus (STN) by 2003 for PD. In part, because of demonstrated tolerability as well as encouraging clinical outcomes, DBS has qualified under the FDAs Humanitarian Device Exception (HDE) for a number of neurologically rooted disorders including stimulation of GPi and STN for dystonia in $2003{ }^{8)}$ stimulation of the anterior limb of the internal capsule for obsessive compulsive disorder (OCD) in 2009,9) and closed-loop stimulation for epileptic indications in 2013. ${ }^{10)}$ The pipeline for

Received July 7, 2015; Accepted July 28, 2015 evaluating the use of DBS for novel indications begins with animal models or encouraging findings in case studies, progressing to small randomized trials, and culminating in large, multi-site, doubleblinded clinical trial like the Stimulation of the Anterior Nucleus of the Thalamus for Epilepsy (SANTE) trials backed by Medtronic. Advances in surgical techniques, clinical needs, and basic science findings also contribute to the fluctuating levels of interest a given innovative procedure receives. Often these variables necessitate the re-evaluation of DBS for indications formerly investigated such as depression as well as for novel indications like traumatic brain injury. ${ }^{11,12)}$

As a tool to treat refractory cases of neurologically based disorders, DBS has noteworthy potential because of the scope of disorders it has the capacity to address. Results from the 2008-2012 Mental Health Surveillance Study indicated that among adults aged 18 and older, approximately $22.5 \%$ of the population had at least one diagnoses of a mental disorder when including adjustment disorder and substance abuse disorder. ${ }^{13)}$ Of these 51.2 million people, an estimated 9.6 million adults suffer from severe mental illness characterized as resulting in serious functional impairment, which significantly interferes with or limits one or more 
major life activity. When added to the millions of people suffering from Alzheimer's disease (AD) induced dementia, intractable neuropathic pain, and movement disorders like PD, a very sizeable patient population are realized.

With the majority of patients clinically classified as under-treated and conventional neuropsychiatric drug discovery routes proving inefficient, adjunctive treatments have been increasingly utilized to augment conventional care. Such treatments range in approach as well as clinical clout; these include lifestyle modifications such as ketogenic diets, talk or physical therapy like Tai chi, off-label prescription of pharmaceuticals, and neuromodulatory techniques. ${ }^{14)}$ The latter category comprises a significant and growing number of adjunctive treatments with a mixed history of effectiveness dating back to the 1900s. DBS, which demonstrates the greatest level of treatment versatility as well as clinical confidence, along with vagus nerve stimulation (VNS), electroconvulsive therapy (ECT), transcranial direct current stimulation (tDCS), transcranial magnetic stimulation (TMS), and recently developed optogenetic methods comprise this growing neuromodulatory armamentarium.

\section{DBS for PD}

The principal reason why DBS is held with high regard by clinicians and researchers is because of its demonstrated efficacy for treatment of PD and its related indications. A progressive motor system disorder resulting from degradation of dopamineproducing cells originating from the substantia nigra pars compacta; current treatments for PD can address dopaminergically related symptoms of the disease on the order of years but they do not cure the degeneration itself. ${ }^{15-17)}$ Routinely diagnosed in patients over 50, PD often presents as asymmetric tremor in the distal portion of the limbs but can also appear as stiffness or rigidity, primarily in the face and upper limbs. Disabilities associated with PD also include soft voice, masked face, shuffling gait, disequilibrium, constipation, and orthostatic hypotension as well as nonmotor symptoms such as apathy, depression, and cognitive decline. ${ }^{18-20)}$ In the United States, medication cost for PD patients is from $\$ 1,000$ to $\$ 6,000$ per year with annual risk of hospitalization exceeding $30 \%$, contributing to a national burden of approximately $\$ 23,000$ per patient. ${ }^{18,21)}$ As one in three patients will be unemployed within a year of diagnosis these financial burdens can vary significantly and affect the quality of life and will exert a progressively greater economic impact as the age distribution in America approaches that of countries like Japan. ${ }^{18,22)}$
Early diagnosis of PD is challenging, and although longitudinal disease models indicate a prodromal dementia stage characterized by declines in working memory, visuospatial processing, and bradyphrenia beginning about 5 years prior to motor deterioration, can often be confused with effects of aging. ${ }^{20)}$ Without the ability to look for revealing biomarkers that clinicians could otherwise use to generate robust diagnostic measures, these relatively ambiguous cognitive deficits are our best indicators of PD onset. Although a traditional diagnostic blood test may not be available for PD, novel measures like olfactory ability as well as tone in vocal cords and tremor detected by smart phone software applications may elucidate clinically useful, non-invasively gathered diagnostic data. ${ }^{23)}$ When needed, cerebrospinal fluid analysis and positron emission tomography (PET) scans can elucidate more detailed information concerning pathology. ${ }^{24,25)}$

Patients' best treatment course is levodopa taken in conjuncture with a decarboxylase inhibitor; the combination of which confines the conversion of levodopa to dopamine within the blood brain barrier. Unfortunately, this treatment produces significant dyskinesia in 5 to 10 years when patients' tolerance to the medication necessitates relatively high doses. Whether from the symptoms of PD or adverse effects of their levodopa treatments, patients in the advanced stages of the disease can experience significantly impaired quality of life. Fortunately, DBS has been shown to attenuate this pharmacologically induced dyskinesia as well as tremor seen in pronounced $\mathrm{PD}$, making it very appealing as an intervention for advanced cases. ${ }^{26)}$ Primary neuroanatomical targets for PD DBS are the STN and GPi, which can both be implanted unilaterally or bilaterally. The majority of medical institutions have traditionally favored the STN over the GPi, resulting in bilateral implantation of the STN being the most commonly performed procedure. Recent findings from randomized trials indicate that a consensus on which target is most efficacious is still being formed, and will likely not result in one becoming the overwhelming standard. Rather, different permutations of DBS procedures will likely be best suited for different types of PD cases.

Published in 2012, a large US Veteran's Affairs multi-site randomized trial followed outcomes of 89 GPi patients and 70 STN patients for 36 months, showing both targets to have similar motor function outcomes relative to patients' baselines. ${ }^{27)}$ Quality of life measures also showed similar significant improvements following stimulation, but the STN group did report slightly worse scores on the Mattis Dementia Scale at 6 months than the GPi group ( $p=0.03)$. In 2013, a Dutch group announced results 
from a double-blinded comparison of 65 GPi and 63 STN patients, also finding no significant differences in primary outcomes. Interestingly, they reported no large differences in effect on mood and cognition, but did observe a meaningful difference in the off-drug phase of the experiment in which the STN group displayed a markedly greater improvement. In line with these findings, a substantial meta-analysis by a group from the Second Affiliated Hospital of Chongqing Medical University reported on 563 patients across six trials. Data mining work published prior to April 1, 2013, broadly supports the claims that both targets significantly improve motor function, both improve quality of life measures, the STN allows for great reduction in dose of medication, and the GPi is the preferred target for those with cognitive function concerns. ${ }^{28)}$

The unilateral vs. bilateral treatment choice is another judgment being debated and has been more poignantly assessed in a group of recent literature. Hershey et al. found similar outcomes on motor function and working memory for bilateral stimulation and unilateral stimulation of the more affected brain region. ${ }^{29)}$ In findings published in 2010 from the National Institutes of Health (NIH) COMPARE cohort, 52 patients were randomized between STN and GPi unilateral implantation, with the opportunity to have their contralateral side similarly addressed 6 months later. Outcomes indicate that unilateral DBS was efficacious for a subset of patients who had especially pronounced asymmetric PD symptoms. Additionally, the majority of such cases were GPi targets; patients implanted in the STN were 5.2 times more likely to undergo bilateral implantation than their GPi counterparts, with the most common reason for undergoing bilateral implantation being poor control of symptoms with one lead. ${ }^{30)}$ If unilateral implantation in the GPi were therapeutically equivalent to bilateral STN or GPi in certain PD subpopulations, it would be of great value in identifying them and limiting the surgical exposure that patients needed to sustain.

Although these results do indicate that additional refinement of patient selection criteria is needed, the consensus continues to be supportive of the overall efficacy of DBS for PD. Crucially, recent long-term studies also support the efficacy of DBS, but are limited in that they largely report on solely bilateral STN patients. A Rush University group published preliminary data from a proposed 100 patients cohort in which long-term outcomes of bilateral STN implantation are being measured with the unified Parkinson's disease rating scale (UPDRS) as well as measures of patient satisfaction and quality of life. Eleven patients' responses indicated satisfaction was maintained at an average of 10 years after surgery with higher quality of life at time of survey despite progressive disability. Patients also indicated that they would undergo the surgery again, at a younger age if possible. ${ }^{19)} \mathrm{A}$ similar, larger study was carried out in China surveying 195 bilaterally implanted STN patients using the UPDRS at 1 year, 3 years, and 5 years after surgery-both on and off medication. Patients indicated significant improvements ( $p<0.001$ ) in tremor, rigidity, akinesia, postural stability, gait, and cumulative score in the motor examination portion of the UPDRS as well as in the writing, freezing of gait, and overall score in the activity of daily living portion of the UPDRS, both 3 years and 5 years after surgery vs. baseline. ${ }^{31)}$ The survey also reported one fatality due to an intraoperative intracerebral hemorrhage, as well as 26 hardware-related complications affecting 20 patients. Notably, 12 complications were erosions and/or infections, 7 of which occurred beyond 12 months after implantation. ${ }^{31)}$

Cumulatively, these reports indicate some ambiguity for how a given patient may respond to a particular set of treatment parameters; but in general for patients with cognitive concerns, the GPi is likely the more efficacious target, while for patients who do not tolerate levodopa treatment well, the STN may be preferred. Patient outcomes and satisfaction are broadly positive with regard to control of dopaminergically related symptoms and can be extended for over a decade. For treatment of axial impairments and cognitive decline seen in advanced PD, however, modulation of these nuclei do not meet patients' needs. This has prompted investigation of novel targets such as the pedunculopontine tegmental nucleus (PPTg), caudal zona incerta, and substantia nigra pars reticulate (SNr). However, recent evidence indicates these nuclei to be too heterogeneous to effectively target and our understanding of exactly how these regions contribute to axial dysfunction to be too primitive. ${ }^{32-34)}$ It is possible that future procedures will incorporate multi-site modulation to address the full gamut of dopaminergic, axial, and cognitive impairments advanced PD patients endure. ${ }^{11,32,35-39)}$ It is certain that clinicians will need to keenly match patients' symptoms with known outcomes of a number of neuroanatomic targets, unilateral and bilateral stimulation, as well as various stimulatory parameters including frequency, intensity, pulse width, and constant-current vs. voltage-controlled stimulation. ${ }^{40-43)}$

\section{DBS in essential tremor (ET)}

DBS has also demonstrated an effective relief from ET, the first indication that the Food and Drug 
Administration (FDA) approved the procedure in 1997. The NIH broadly defines tremor as a type of rhythmic shaking movement that is not necessarily specific to a given body part. ET is the most common type of tremor with an estimated prevalence of up to $5 \%{ }^{44-46)} \mathrm{ET}$ is a neurologically a rooted condition characterized by its lack of an identifiable cause as well as its progressive disease course. ${ }^{47-49)}$ Diagnostic criteria for the disorder include bilateral, often symmetrical tremor of the hands, forearms, voice, head, and leg tremor. ${ }^{50)}$

Some cases of ET can be treated pharmacologically with off label prescription of beta blockers, tranquilizers, anti-seizure medication, or even Botox injections for certain cases of head and voice tremors. ${ }^{51,52)}$ These medications offer some relief of symptoms but only reduce tremor by approximately $60 \%{ }^{53,54)}$ DBS is significantly more effective than medicinal treatments of ET, reducing tremor on average by $90 \%$ although some studies report over 7\% complication rate within the first 90 days. ${ }^{56-57)}$ Interesting, Verla et al. found that the rates of complication for severe complications like hemorrhage and infection did not significantly increase with age indicating that perhaps patients currently thought to be outside the therapeutic window will tolerate the procedure well. ${ }^{57)}$

Surgeons generally target the ventral intermediate nucleus (Vim) of the thalamus for ET treatment. ${ }^{56}$ Vim DBS in ET was first performed in 1991 and has been quite successful in many studies, reducing tremor and providing long-term relief in some patients. ${ }^{58)}$ However, recent research shows that the Vim might be a less optimal target than the posterior subthalamic area (PSA), especially for patients who do not respond well to Vim thalatomy. ${ }^{59,60)} \mathrm{A}$ review of the literature performed by Chopra et al. from the Mayo Clinic found both targets appear to be efficacious and well tolerated, but also indicated that long-term follow-up work on PSA patients is necessary to assess its merit. ${ }^{61)}$ For Vim implantation, studies have shown that more than $70 \%$ of ET patients experienced waning benefits of DBS at around 56 months after initial implantation. ${ }^{62)}$ However, reports have also shown that DBS in the Vim can be an effective way of reducing tremor even 12 years after implantation. ${ }^{63}$

Another novel target, the dentato-rubro-thalamic tract (DRTT) was assessed with the aid of diffusion tensor imaging but results from the small cohort of five patients were not encouraging. ${ }^{64)}$ Essential voice tremor (EVT), an indication closely related to ET, was recently treated with DBS by a Stanford group pioneering a comprehensive intraoperative voice evaluation approach which may lead the establishment of a new approach for subtypes of ET. ${ }^{65)}$ Patients suffering from EVT display a pronounced tremulous voice often associated with social embarrassment and loss of quality of life.

\section{DBS in dystonia}

DBS has also been approved in the treatment of dystonia. Dystonia is an often refractive, heterogeneous neuromuscular disorder characterized by abnormal muscle contractions causing repetitive involuntary movements or irregular postures. The majority of dystonia cases have unknown causes, but some are known to be genetic in origin. First used to treat dystonia in 1977, the procedure became widespread by the turn of the century. DBS targeting the GPi is most common in the treatment of dystonia, and has repeatedly shown efficacy over the years. ${ }^{66-70)} \mathrm{A}$ recent meta-analysis of the literature found strong evidence supporting the use of DBS for cervical, primary, or segmental dystonia, especially when symptoms can be traced to mutations of the DYT1 gene. ${ }^{71)}$ Long-term GPi-DBS is effective in patients presenting with DYT6 and non-DYT dystonia as well, but the effect of DBS is more variable in patients with DYT6. ${ }^{72)}$ In a study off 22 young adult dystonia patients, Haridas et al. showed that DBS in dystonia patients under the age of 21 is a safe method of treatment. ${ }^{73)}$ This is particularly important for the viability of DBS-treated dystonia, as childhood and young adulthood onset is common for dystonia patients. Other clinical trials show that DBS is more effective in children than in adults. ${ }^{74)}$ Although modulation of the GPi is efficacious, the treatment brings with it a risk for mild yet significant impairment of speech. ${ }^{75)}$ DBS offers a safe and effective way of reducing dystonia symptoms in cases that do not respond to medicinal treatments.

\section{DBS for epilepsy}

Because of the ability of DBS to modulate electrical activity it would seem to be uniquely suited to address cases of refractory epilepsy. In 2013, closed loop stimulation was approved as an HDE by the FDA to treat intractable cases of epilepsy with expanding approval expected in the near future. Epilepsy as a clinical diagnosis generally describes chronic, spontaneous seizures, which can be further classified based on how the epileptic activity arises, spreads, and extinguishes for a given patient. Causes of epilepsy include genetic predisposition, pharmacologically induced neurological adaptations, mechanical injuries as seen in traumatic brain injury (TBI), and deleterious developmental events. Even with the best clinical care, about a third of all epileptics will receive insufficient care. Prior to 
the use of DBS as a treatment, surgical intervention entailed resective brain surgery until the turn of the 20th century. ${ }^{76)}$ In 1997,VNS was approved by the FDA for the treatment of epilepsy, but with this treatment seizure freedom is rare and $25 \%$ of patients receive no benefit from the procedure. ${ }^{77}$

The anterior nucleus of the thalamus (ANT) is a particularly interesting target, and as such was the focus of the Medtronic Inc. that sponsored Stimulation of the Anterior Nucleus of the Thalamus for Epilepsy (SANTE) trials. Out of 157 patients, 110 qualified to undergo bilateral stimulation of the ANT at 1 of the 17 facilities in the United States. ${ }^{78)}$ The study reported a $56 \%$ reduction in seizure frequency 2 years after implantation and although approval was granted in Europe and Canada, the FDA did not. Despite the shortfall of the SANTE trials in the eyes of the FDA, the ANT continues to be a target of interest for treatment of epilepsy, and Medtronic continues to support clinical trials in the international market. Advances in intraoperative electrode positioning using computed tomography provided by devices like Medtronic's O-arm and novel electrode implant trajectories may be techniques that assist in bringing the effectiveness of ANT DBS up to the required levels. ${ }^{79,80)}$ These new techniques may be especially effective for targeting the ANT because of the sequestered location of the nucleus and heterogenic local cellular composition.

Although ANT has garnered the most attention in the last decade; there are other strong candidates as well. Medtronic and George Washington University are currently sponsoring a trial to evaluate the effect of stimulation of the fornix in intractable mesial temporal lobe epilepsy. The hippocampus (HC) and related projections like the fornix are the primary regions of interests for temporal lobe epilepsy (TLE). ${ }^{81-83)}$ Because TLE accounts for the greatest number of epileptic diagnoses, the HC has long been known to be implicated in this subset of disorders. ${ }^{84)}$ As a result, resective surgery of this region has historically been relatively common and is still carried out in some cases. ${ }^{76)}$ Compared to resection, DBS places minimal additional risk to the patient's health as resective surgery candidates often undergo electrode placement in the $\mathrm{HC}$ as a means to evaluate seizure localization. Significant challenges exist to develop the HC as a viable surgical target due to its notably heterogeneous composition and recruitment into most major neurologic functions. Likely because of this anatomic complexity, clinical trials have reported mixed findings.

Another target of interest, the centromedian nucleus of the thalamus (CMN), is known to be integral to neurologic gate-keeping which is hypothesized to be altered in epileptics. Small-scale clinical trials have yielded encouraging results of reducing generalized seizures by $>50 \%$ up to a year after implant. ${ }^{85,86)}$ However, results have not been uniformly encouraging, indicating necessary refinement in stimulatory parameters and/or superior patient selection criteria. Interestingly, for the CMN as well as ANT there is a therapeutic effect of lead placement without current that often lasts for several months. ${ }^{78,86)}$

\section{DBS for Gilles de la Tourette (GTS)}

Patients diagnosed with Tourette's syndrome (TS) display repetitive motor and vocal behaviors on a broad spectrum. ${ }^{87,88)}$ Often in proportion to the severity of their symptoms, patients respond to conventional care including relatively new treatments such as intramuscular injections of botulinum toxin. Patients who present with TS as well as other comorbidities, "TS plus", are the population most likely to benefit from DBS as they are often refractory to care. Although much remains unknown concerning the causes of the disorder, genetic predisposition has been known to play a role in some cases. What is known about the etiology of TS comes from imaging studies that have elucidated the likely role of impaired thalamic, dopaminergic system, and basal ganglia function. However, it is challenging to separate which factors contribute to comorbidities and which to TS itself. ${ }^{89,90)}$

Although the number of implanted patients is only around 100, most of these cases have been reported to respond well to DBS. ${ }^{87,91,92)}$ Based on these studies, the regions of the thalamus, globus pallidus, and nucleus accumbens (NAc) have received the most clinical attention. Among the many case reports, an Italian group headed by Dr. Servello has crucially published sizeable patient cohorts of bilateral thalamic intralaminar/ventralis oralis complex implants with follow-up data acquired at 6 years post surgery. ${ }^{93,94)}$

The findings of Servello et al. are nearly uniformly encouraging, and they are not the only team whose work is indicating such. An Australian group evaluating the anteromedial globus pallidus interna published that 10 of their 11 patients reported improvement in tic severity while 6 of these patients had more than $50 \%$ overall reduction in tics for at least a 3-month period. ${ }^{95)}$ In line with these findings, a Mayo Clinic group targeting the bilateral thalamic centromedian/ parafascicular complex found a $60 \%-80 \%$ mean reduction in tics as measured by the Yale Global Tic Severity Scale at the 1 year follow-up point in their three-patient study. ${ }^{96)}$

Smith and Spindler from the Perelman School of Medicine recently conducted a review of case 
studies and small trials for hyperkinetic movement disorders and found that for treatment of GTS and tardive syndromes, the literature supported the efficacy of DBS.97) Evaluation of GTS was aided by two randomized, double-blind studies that cumulatively assessed 11 patients. ${ }^{98,99)}$ Due to these promising findings, there are currently at least five clinical trials expected to report on the efficacy of DBS for GTS in the next year with several others evaluating TMS and tDCS to the same end, but significant challenges remain in addressing the true efficacy of DBS for GTS as evidenced by disappointing results from a randomized trial utilizing Neuropace's responsive neurostimulation system reported in 2013. ${ }^{100)}$

These encouraging findings would indicate that DBS for TS seems to be effective for over $90 \%$ of patients to varying degrees. ${ }^{101)}$ When considering that most of these data come from case reports or small cohorts being implanted in different targets by different clinicians, it is especially impressive. Work showing the potential for amelioration of "TS plus" cases should be the focus of future study as these cases are in particularly dire need of adequate care. ${ }^{102,103)}$ Overall, TS is one of the most promising rising indications for DBS. ${ }^{101,102)}$ Clinical trials are currently recruiting participants at the University of Western Australia, University of Florida, and John Hopkins while results from trials carried out at University College London are forthcoming.

\section{DBS for depression}

The World Health Organization estimates that over 350 million people suffer from major depressive disorder (MDD). In Japan, a top-down costing approach estimated the national burden of depression to be $\$ 11$ billion in $2008 .{ }^{104)}$ In America, over $2 \%$ of adults will suffer from severe depression in a given 12-month period. ${ }^{105)}$ Like most psychiatric disorders, MDD is challenging to treat due to lack of treatment options as well as complex social stigmas and complicating comorbidities. Because of need, DBS has been increasingly assessed as a potential option for patients afflicted with refractory disease courses.

The first wave of trials evaluated the anterior limb of the capsula interna (ALIC), anterior cingulate cortex (Cg25), ventral striatum, medial forebrain bundle (mFB), and subcallosal cingulate gyrus (SCG). ${ }^{106)}$ The ALIC, mFB, and SCG are especially deserving attention as long-term data is available for analysis. ${ }^{107)}$ The SCG was targeted in 17 patients with refractory MDD by Holtzheimer et al., and showed reduction in reported levels of depression in $92 \%$ of patients. Impressively, these results are
2 years post implantation. ${ }^{108)}$ This finding supports Mayberg's proposed circuitry for depression, as well as pharmacologic and imaging studies that indicate hypermetabolism of the SCG is at work behind MDD. ${ }^{77,109,110)}$ The ventral striatum and related reward centers havebeen another focus for researchers. Ten patients implanted in the NAc reported improved cognition and vision in 1 year after treatment. ${ }^{111)}$

Encouraged by these and related findings, Medtronic sponsored a 30-patient, multi-site randomized sham-controlled trial evaluating the effect of ventral capsule/ventral striatum DBS on refractory MDD. ${ }^{12)}$ In the first such randomized controlled trial for MDD published in 2014, patients were blinded to their treatment for 16 weeks, followed by open-label treatment. Although the desired 50\% improvement in Montgomery-Åsberg Depression Rating Scale was not achieved, patients did report a range of $20-26.7 \%$ improvement in the open-label continuation phase. These findings would indicate that additional randomized controlled trials evaluating other anatomic targets or incorporating alternate surgical approaches and stimulatory parameters will be likely best suited for the treatment of MDD. The medial forebrain bundle, may be such a target. ${ }^{113)}$

\section{Addiction}

Addiction describes a pattern of ingrained, repetitive behavior that is engaged despite risks or deleterious consequences. The DSM V includes gambling and substance abuse as examples of specific addictions. Proposing adjunctive use of DBS for refractory cases of neuropsychiatric disorders is always a complicated undertaking, but with addiction there are additional ethical questions and concerns over patient's ability to cohere to a regular treatment regimen. Additionally, it is not clear whether deleterious drug-induced neurologic changes contribute as greatly to uncontrolled substance use as environmental or social factors. For these reasons patient selection is crucial.

Proposals for use of DBS to treat addiction have drawn evidence from animal models and imaging studies in conjunction with clinical observation of unintended effects of NAc stimulation. Changes in several brain regions have been correlated to addictive behaviors, but it is the dopaminergic pathways incorporating the NAc and related structures that have received the most attention. ${ }^{14-116)}$ Implanted in the NAc for the purpose of addressing anxiety and depression, a 54-year-old patient was able to significantly reduce the amount of alcohol he was consuming. ${ }^{117)}$ The treatment did not affect his 
intended behavioral outcome but the effect on the patient's long-standing alcoholism was significant itself.

A group headed by the same researchers who noticed this unintended effect tracked the smoking behavior of 10 patients after they began receiving NAc DBS for refractory anxiety, OCD, or TS in 2011. While receiving stimulation, $30 \%$ enrolled reported cessation of smoking. The most damaging substance addictions such as alcohol, nicotine, and heroine have all been reported to respond positively to stimulation in some cases. ${ }^{118,119)}$ In Germany, a recent five patient trial attempted to treat severe alcoholism with off-label bilateral NAc DBS and found encouraging results. All patients reported immediate cessation of cravings following stimulation. ${ }^{120)}$ Two patients were abstinent from alcohol for over 4 years, while for the three cases where stress was heavily implicated in alcohol abuse, the frequency and intensity of relapses was heavily attenuated. Additionally, one patient suffered broken electrode leads, following replacement and reported a therapeutic effect equal to what was initially felt following surgery. No adverse effects of surgery were reported, and although one patient exhibited a transient episode of hypomania, adjustment of stimulation settings resulted in symptoms abating. Although overall very positive, findings from this study cannot be analyzed with a high level of confidence because patients were not blinded to their treatment. It is encouraging to see that in the case of the patient with broken leads, reported therapeutic effects were in line with whether or not current was effectively being delivered. ${ }^{120)}$

With data accumulation in the early stages, it is difficult to know how much promising modulation of the reward the circuitry holds for treatment of addiction, but with the economic and disease burden of addiction being so and preliminary results, it appears to be worth further investigation. Several clinical trials are recruiting opioid or alcohol dependent patients for NAc DBS on the international stage, but at the time of writing results are forthcoming. Of particular interest will be two trials being carried out by the German Research Foundation in response to positive findings by Voges et al. Additionally, promising optogenetic work carried out in animal models has indicated that activation of metabotropic glutamate receptors may normalize drug-adaptive behavior. In 2015 a Swiss group reported that such an effect could also be elicited by low-frequency DBS and selective blocking of D1 receptors. ${ }^{121)}$ Such findings will likely result in optimized clinical trial stimulation parameters and improved outcomes.

\section{DBS for Obesity}

Obesity presents some of the same challenges as addiction to clinicians who must gauge whether a given patient would truly benefit from neurologic intervention as well as whether they could adhere to a larger treatment plan including lifestyle modifications. Worldwide obesity is a growing epidemic with the WHO estimating 600 million people have a BMI $>30 \mathrm{~kg} / \mathrm{m}^{2}$. This disease state is strongly linked to cardiovascular disease, diabetes, and stroke. Perhaps even more poignantly, obese individuals suffer from a significantly reduced quality of life. ${ }^{122)}$ Nonetheless it can seem like an overstep to address a metabolic imbalance with neurosurgical measures, but when considering the rates that patients opt for often ineffective bariatric surgery it does not seem like a radical treatment. ${ }^{123,124)}$

In a review by Halpern et al., several targets of interest are outlined that are largely supported by case reports as well as known neurologic functions. ${ }^{116,125,126)}$ One such region is the hypothalamus, which regulates feeding behavior through the endocrine system. The ventromedial hypothalamus (VMH) is a specific subregion being investigated, but current evidence links stimulation of this region with adverse behavioral reactions linked to anxiety and fear response. ${ }^{127)}$ In 2008, Hamani et al. carried out bilateral implantation of the $\mathrm{VMH}$ in a morbidly obese individual resulting in feelings of déjà vu and related phenomena but had no effect on hedonia. ${ }^{128)}$ Another region of the hypothalamus, the lateral hypothalamus (LH), is also under investigation as modulation of its activity may lead to increased metabolic rate itself. ${ }^{129)}$ To assess the viability of DBS, a human pilot study was conducted out of the Allegheny General Hospital in Pittsburgh, PA. In 2013, they reported three intractable obese patients who were implanted in an effort to see how safely such a procedure could be done in this patient population. ${ }^{130}$ ) During the 3-year follow-up period no serious adverse effects were reported. DBS was programmed using standard parameters from movement disorder work, so no significant weight loss was observed, but promising data showing increased resting metabolic rate indicate such a result is a real possibility.

\section{Animal Models}

Findings from animal models inform future clinical investigations, but due to the number of such studies it can be challenging to keep informed on promising work. Grouped by indications of interest, recent work in rodents and higher mammals is summarized in Table $1 .^{121,131-149)}$ 


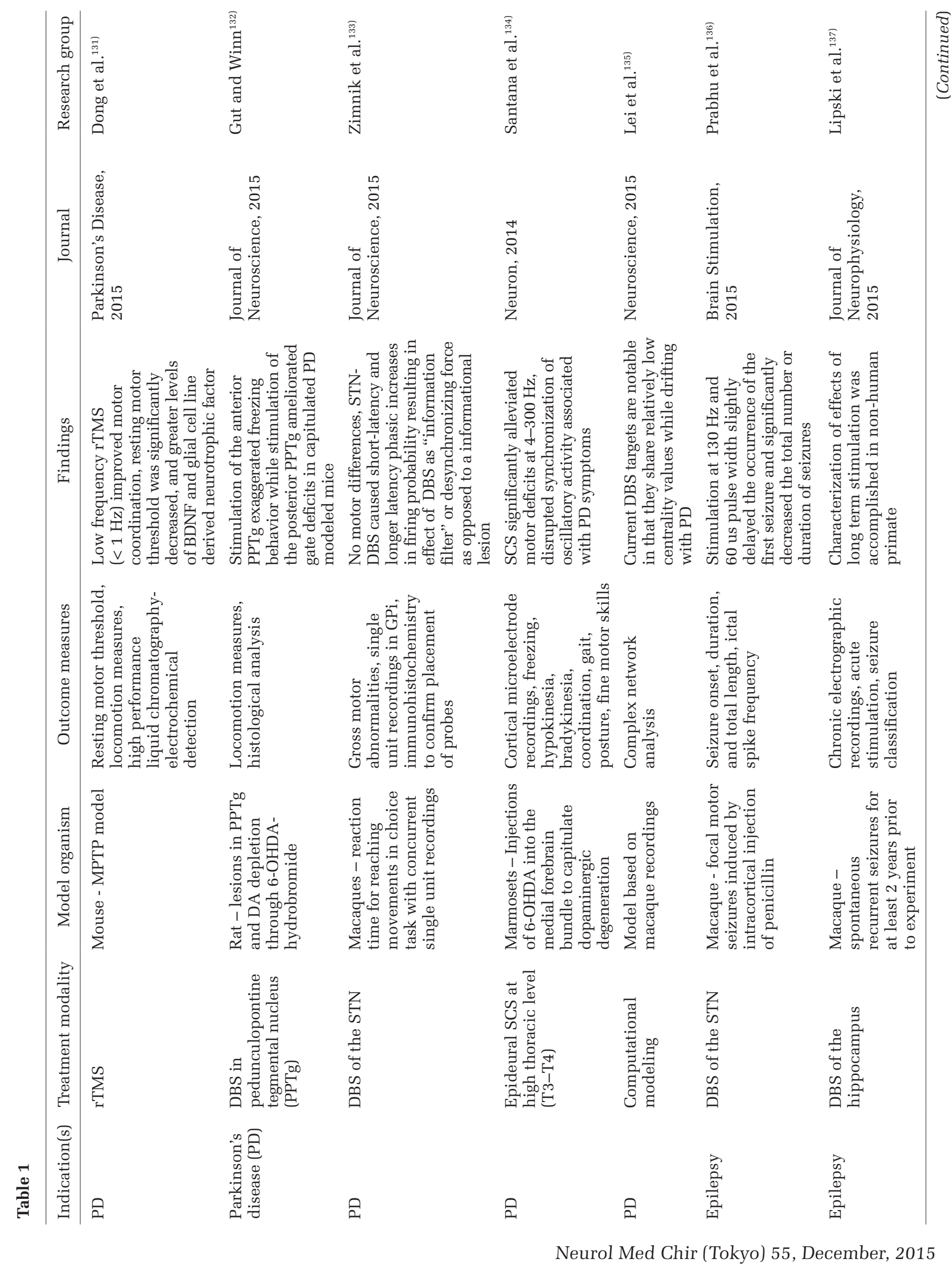




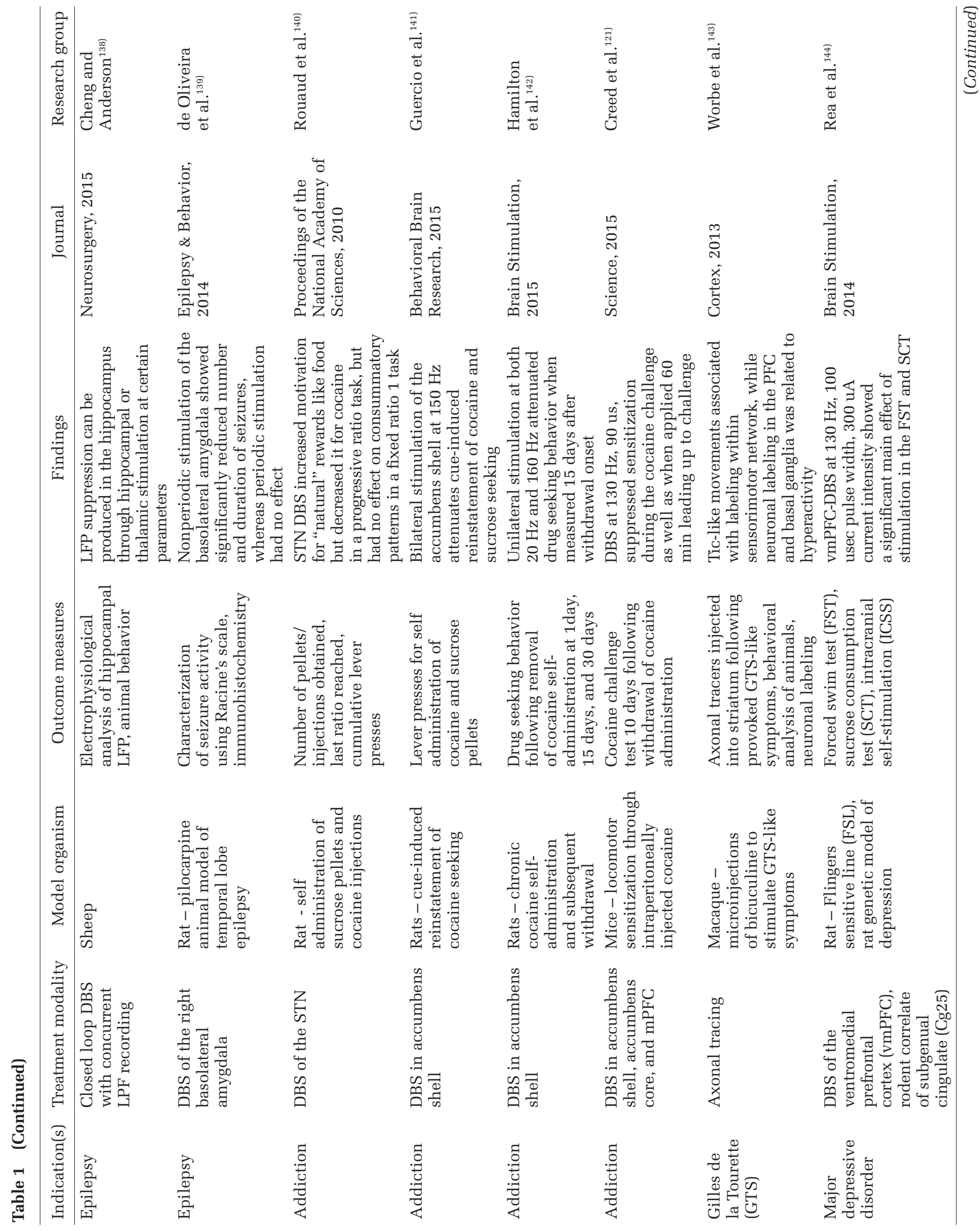

Neurol Med Chir (Tokyo) 55, December, 2015 


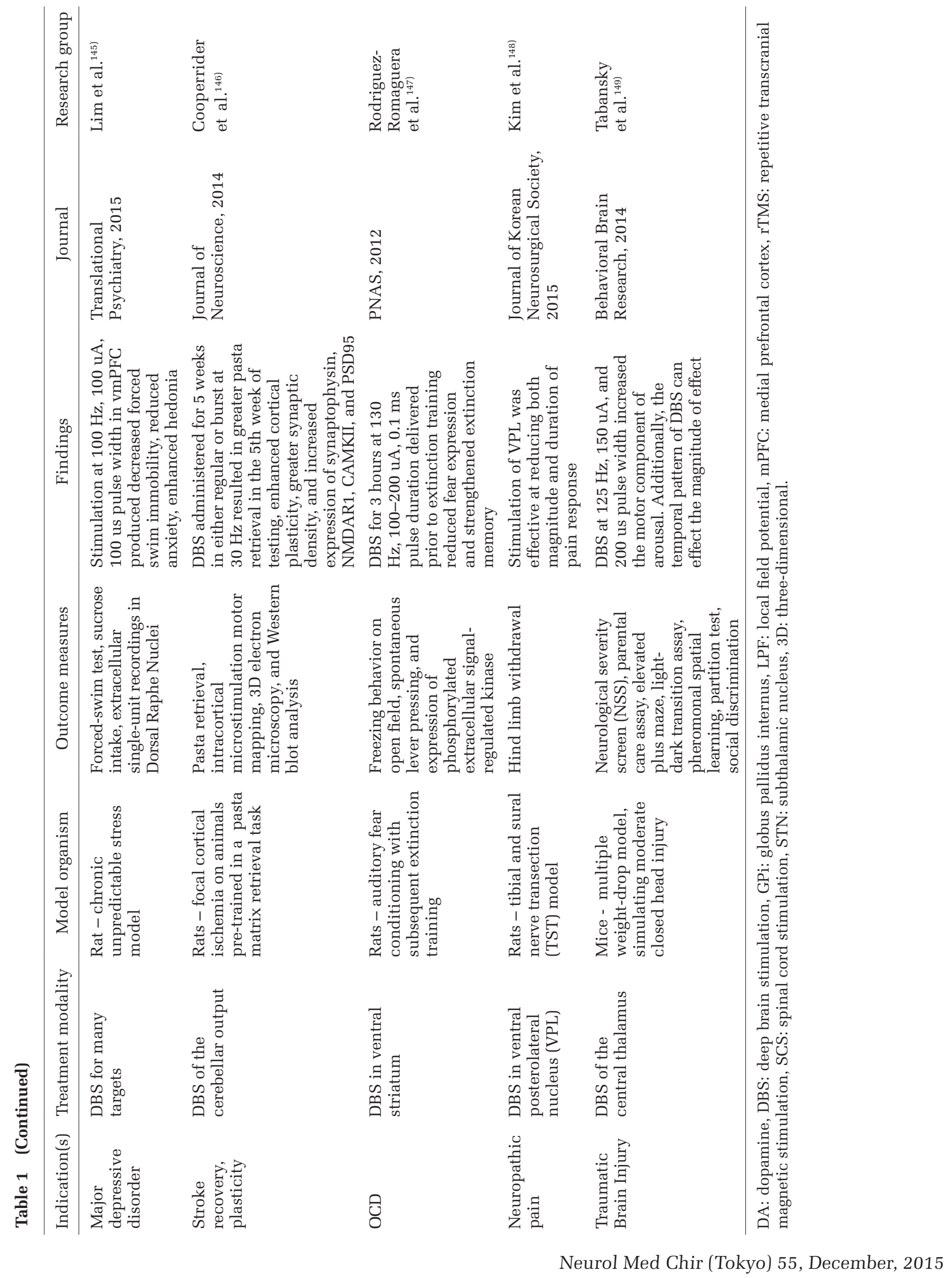




\section{Conclusion}

With over 700,000 stimulation devices in use, internationally ranging from sacral nerve stimulators for urinary incontinence to cochlear implants for hearing loss, and with revenue nearing three billion dollarsit is clear that technologies like DBS are disrupting conventional treatment options. ${ }^{150)}$ DARPA's recently disclosed \$70 million Brain Research through Advancing Innovative Neurotechnologies specifically addresses the development of novel, wireless devices like DBS hardware, further highlighting the attention modulatory devices are receiving from the larger academic community. ${ }^{151)}$ Miniaturization of scopes that can be used intraoperatively as well as advances in DBS hardware will continue to make therapeutically powerful but technically difficult targets like the HC or ANT more easilyy. ${ }^{10,32,83,152)}$ The coming decades will see a proliferation of DBS procedures, with the major limitations continuing to be acquiring resources to pursue double blinded clinical trials as well as long-term monitoring.

\section{Conflicts of Interest Disclosure}

The authors, Anand Tekriwal and Dr. Gordon Baltuch, declare no conflicts of interest.

\section{References}

1) Connolly PJ, Halpern $\mathrm{CH}$, Baltuch GH, Danish SF, Jaggi JL: Implications for programming strategy of the location of the active contact in subthalamic nucleus deep brain stimulation. J Clin Neurosci 19: 1029-1031, 2012

2) Connolly PJ, Kilpatrick M, Jaggi JL, Church E, Baltuch GH: Feasibility of an operational standardized checklist for movement disorder surgery. A pilot study. Stereotact Funct Neurosurg 87: 94-100, 2009

3) Halpern C, Hurtig H, Jaggi J, Grossman M, Won M, Baltuch G: Deep brain stimulation in neurologic disorders. Parkinsonism Relat Disord 13: 1-16, 2007

4) Kramer DR, Halpern CH, Buonacore DL, McGill KR, Hurtig HI, Jaggi JL, Baltuch GH: Best surgical practices: a stepwise approach to the University of Pennsylvania deep brain stimulation protocol. Neurosurg Focus 29: E3, 2010

5) Kramer DR, Halpern CH, Connolly PJ, Jaggi JL, Baltuch GH: Error reduction with routine checklist use during deep brain stimulation surgery. Stereotact Funct Neurosurg 90: 255-259, 2012

6) Kramer DR, Halpern CH, Danish SF, Jaggi JL, Baltuch GH: The effect of intraventricular trajectory on brain shift in deep brain stimulation. Stereotact Funct Neurosurg 90: 20-24, 2012

7) Syre P, Bohman LE, Baltuch G, Roux PL, Welch WC: CSF leaks and their management following anterior cervical discectomy and fusion: a report of 13 cases and a review of the literature. Spine (Phila Pa 1976) 2014 [Epub ahead of print]

8) Schultz DG: Medtronic Activa ${ }^{\circledR}$ Dystonia Therapy in: F.a.D. Administration (Ed.), Rockville MD, 2003

9) Tillman D-B: Reclaim Deep Brain Stimulation for Obsessive Compulsive Disorder (OCD) Therapy in: F.a.D. Administration (Ed.), Food and Drug Administration, Rockville MD, 2009

10) Foreman C: RNS® System, in: F.a.D. Administration (Ed.), Silver Spring, MD, 2013

11) Deco G, Kringelbach ML: Great expectations: using whole-brain computational connectomics for understanding neuropsychiatric disorders. Neuron 84: 892-905, 2014

12) Shin SS, Dixon CE, Okonkwo DO, Richardson RM: Neurostimulation for traumatic brain injury. $J$ Neurosurg 121: 1219-1231, 2014

13) Rhonda S Karg, Jonaki B, Kathryn R. Batts, Valerie L. Forman-Hoffman, Dan Liao, Erica Hirsch, Michael R. Pemberton, Lisa J. Colpe, Sarra L Hedden: Past year mental disorders among adults in the United States: results from the 2008-2012 Mental Health Surveillance Study. CBHSQ Data Review 2014

14) Liu T, Lao L: Tai chi for patients with Parkinson's disease. N Engl J Med 366: 1737; author reply 1738, 2012

15) Yasuhara T, Kameda M, Agari T, Date I: Regenerative medicine for Parkinson's disease. Neurol Med Chir (Tokyo) 55(Suppl 1): 113-123, 2015

16) Fischbach GD, McKhann GM: Cell therapy for Parkinson's disease. $N$ Engl J Med 344: 763-765, 2001

17) Calne DB: Progress in Parkinson's disease. N Engl J Med 310: 523-524, 1984

18) Okun MS: Deep-brain stimulation-entering the era of human neural-network modulation. $N$ Engl J Med 371: 1369-1373, 2014

19) Jessica K, Bichum O, Leonard VM: Patient-centered outcomes of deep brain stimulation in parkinson's disease. (P1.174). Neurology 84(Supplement P1.174): 2015

20) Johnson DK, Langford Z, Garnier-Villarreal M, Morris JC, Galvin JE: Onset of mild cognitive impairment in parkinson disease. Alzheimer Dis Assoc Disord 2015 [Epub ahead of print]

21) Kowal SL, Dall TM, Chakrabarti R, Storm MV, Jain A: The current and projected economic burden of Parkinson's disease in the United States. Mov Disord 28: 311-318, 2013

22) Rodriguez-Violante M, Camacho-Ordoñez A, CervantesArriaga A, González-Latapí P, Velázquez-Osuna S: Factors associated with the quality of life of subjects with Parkinson's disease and burden on their caregivers. Neurologia 30: 257-263, 2015

23) Arora S, Venkataraman V, Zhan A, Donohue S, Biglan KM, Dorsey ER, Little MA: Detecting and monitoring the symptoms of Parkinson's disease using smartphones: a pilot study. Parkinsonism Relat Disord 21: 650-653, 2015 
24) Sako W, Murakami N, Izumi Y, Kaji R: Neurofilament light chain level in cerebrospinal fluid can differentiate Parkinson's disease from atypical parkinsonism: evidence from a meta-analysis. J Neurol Sci 352: 84-87, 2015

25) Suwijn SR, van Boheemen CJ, de Haan RJ, Tissingh G, Booij J, de Bie RM: The diagnostic accuracy of dopamine transporter SPECT imaging to detect nigrostriatal cell loss in patients with Parkinson's disease or clinically uncertain parkinsonism: a systematic review. EJNMMI Res 5: 12, 2015

26) Chiken S, Nambu A: Mechanism of deep brain stimulation: inhibition, excitation, or disruption? Neuroscientist 2015 [Epub ahead of print]

27) Weaver FM, Follett KA, Stern M, Luo P, Harris CL, Hur K, Marks WJ, Rothlind J, Sagher O, Moy C, Pahwa R, Burchiel K, Hogarth P, Lai EC, Duda JE, Holloway K, Samii A, Horn S, Bronstein JM, Stoner G, Starr PA, Simpson R, Baltuch G, De Salles A, Huang GD, Reda DJ; CSP 468 Study Group: Randomized trial of deep brain stimulation for Parkinson disease: thirty-six-month outcomes. Neurology 79: 55-65, 2012

28) Liu Y, Li W, Tan C, Liu X, Wang X, Gui Y, Qin L, Deng F, Hu C, Chen L: Meta-analysis comparing deep brain stimulation of the globus pallidus and subthalamic nucleus to treat advanced Parkinson disease. J Neurosurg 121: 709-718, 2014

29) Hershey T, Wu J, Weaver PM, Perantie DC, Karimi M, Tabbal SD, Perlmutter JS: Unilateral vs. bilateral STN DBS effects on working memory and motor function in Parkinson disease. Exp Neurol 210: 402-408, 2008

30) Taba HA, Wu SS, Foote KD, Hass CJ, Fernandez $\mathrm{HH}$, Malaty IA, Rodriguez RL, Dai Y, Zeilman PR, Jacobson CE, Okun MS: A closer look at unilateral versus bilateral deep brain stimulation: results of the National Institutes of Health COMPARE cohort. J Neurosurg 113: 1224-1229, 2010

31) Li J, Zhang Y, Li Y: Long-term follow-up of bilateral subthalamic nucleus stimulation in Chinese Parkinson's disease patients. Br J Neurosurg 29: 329-333, 2015

32) Castrioto A, Moro E: New targets for deep brain stimulation treatment of Parkinson's disease. Expert Rev Neurother 13: 1319-1328, 2013

33) Blomstedt P, Fytagoridis A, Åström M, Linder J, Forsgren L, Hariz MI: Unilateral caudal zona incerta deep brain stimulation for Parkinsonian tremor. Parkinsonism Relat Disord 18: 1062-1066, 2012

34) Moro E, Hamani C, Poon YY, Al-Khairallah T, Dostrovsky JO, Hutchison WD, Lozano AM: Unilateral pedunculopontine stimulation improves falls in Parkinson's disease. Brain 133: 215-224, 2010

35) De Rose M, Guzzi G, Bosco D, Romano M, Lavano SM, Plastino M, Volpentesta G, Marotta R, Lavano A: Motor cortex stimulation in Parkinson's disease. Neurol Res Int 2012: 7, 2012

36) Khan S, Gill SS, Mooney L, White P, Whone A, Brooks DJ, Pavese N: Combined pedunculopontine- subthalamic stimulation in Parkinson disease. Neurology 78: 1090-1095, 2012

37) Lavano A, Guzzi G, De Rose M, Romano M, Della Torre A, Vescio G, Deodato F, Lavano F, Volpentesta G: Minimally invasive motor cortex stimulation for parkinson's disease: a review of literature. J Neurosurg Sci 2015 [Epub ahead of print]

38) Laxton AW, Tang-Wai DF, McAndrews MP, Zumsteg D, Wennberg R, Keren R, Wherrett J, Naglie G, Hamani C, Smith GS, Lozano AM: A phase I trial of deep brain stimulation of memory circuits in Alzheimer's disease. Ann Neurol 68: 521-534, 2010

39) Weiss D, Breit S, Wächter T, Plewnia C, Gharabaghi A, Krüger R: Combined stimulation of the substantia nigra pars reticulata and the subthalamic nucleus is effective in hypokinetic gait disturbance in Parkinson's disease. J Neurol 258: 1183-1185, 2011

40) Sugiyama K, Nozaki T, Asakawa T, Koizumi S, Saitoh O, Namba H: The present indication and future of deep brain stimulation. Neurol Med Chir (Tokyo) 55: 416-421, 2015

41) Lyons MK: Deep brain stimulation: current and future clinical applications. Mayo Clin Proc 86: 662-672, 2011

42) Fukaya C, Yamamoto T: Deep brain stimulation for Parkinson's disease: recent trends and future direction. Neurol Med Chir (Tokyo) 55: 422-431, 2015

43) Okun MS, Gallo BV, Mandybur G, Jagid J, Foote KD, Revilla FJ, Alterman R, Jankovic J, Simpson R, Junn F, Verhagen L, Arle JE, Ford B, Goodman RR, Stewart RM, Horn S, Baltuch GH, Kopell BH, Marshall F, Peichel D, Pahwa R, Lyons KE, Tröster AI, Vitek JL, Tagliati M; SJM DBS Study Group: Subthalamic deep brain stimulation with a constant-current device in Parkinson's disease: an open-label randomised controlled trial. Lancet Neurol 11: 140-149, 2012

44) Tallón-Barranco A, Vázquez A, Javier JiménezJiménez F, Ortí-Pareja M, Gasalla T, Cabrera-Valdivia F, Benito-León J, Molina JA: Clinical features of essential tremor seen in neurology practice: a study of 357 patients. Parkinsonism Relat Disord 3: 187-190, 1997

45) Louis ED: Clinical practice. Essential tremor. N Engl J Med 345: 887-891, 2001

46) Louis ED, Ferreira JJ: How common is the most common adult movement disorder? Update on the worldwide prevalence of essential tremor. Mov Disord 25: 534-541, 2010

47) Zhang K, Bhatia S, Oh MY, Cohen D, Angle C, Whiting D: Long-term results of thalamic deep brain stimulation for essential tremor. J Neurosurg 112: 1271-1276, 2010

48) Hubble JP, Busenbark KL, Wilkinson S, Penn RD, Lyons K, Koller WC: Deep brain stimulation for essential tremor. Neurology 46: 1150-1153, 1996

49) Boockvar JA, Telfeian A, Baltuch GH, Skolnick B, Simuni T, Stern M, Schmidt ML, Trojanowski JQ: Long-term deep brain stimulation in a patient with 
essential tremor: clinical response and postmortem correlation with stimulator termination sites in ventral thalamus. Case report. J Neurosurg 93: 140-144, 2000

50) Kestenbaum M, Michalec M, Yu Q, Pullman SL, Louis ED: Intention tremor of the legs in essential tremor: prevalence and clinical correlates. Mov Disord Clin Pract (Hoboken) 2: 24-28, 2015

51) Simpson DM, Blitzer A, Brashear A, Comella C, Dubinsky R, Hallett M, Jankovic J, Karp B, Ludlow CL, Miyasaki JM, Naumann M, So Y; Therapeutics and Technology Assessment Subcommittee of the American Academy of Neurology: Assessment: Botulinum neurotoxin for the treatment of movement disorders (an evidence-based review): report of the Therapeutics and Technology Assessment Subcommittee of the American Academy of Neurology. Neurology 70: 1699-1706, 2008

52) Hallett M, Albanese A, Dressler D, Segal KR, Simpson DM, Truong D, Jankovic J: Evidence-based review and assessment of botulinum neurotoxin for the treatment of movement disorders. Toxicon 67: 94-114, 2013

53) Warren JB, O’Brien M, Dalton N, Turner CT: Sympathetic activity in benign familial tremor. Lancet 1: 461-462, 1984

54) O’Brien MD, Upton AR, Toseland PA: Benign familial tremor treated with primidone. Br Med J (Clin Res Ed) 282: 178-180, 1981

55) Kalakoti P, Ahmed O, Bollam P, Missios S, Wilden J, Nanda A: Predictors of unfavorable outcomes following deep brain stimulation for movement disorders and the effect of hospital case volume on outcomes: an analysis of 33,642 patients across 234 US hospitals using the National (Nationwide) Inpatient Sample from 2002 to 2011. Neurosurg Focus 38: E4, 2015

56) Deuschl G, Raethjen J, Hellriegel H, Elble R: Treatment of patients with essential tremor. Lancet Neurol 10: 148-161, 2011

57) Verla T, Marky A, Farber H, Petraglia FW, Gallis J, Lokhnygina Y, Parente B, Hickey P, Turner DA, Lad SP: Impact of advancing age on post-operative complications of deep brain stimulation surgery for essential tremor. J Clin Neurosci 22: 872-876, 2015

58) Blomstedt P, Hariz GM, Hariz MI, Koskinen LO: Thalamic deep brain stimulation in the treatment of essential tremor: a long-term follow-up. $\mathrm{Br} J$ Neurosurg 21: 504-509, 2007

59) Blomstedt P, Sandvik U, Tisch S: Deep brain stimulation in the posterior subthalamic area in the treatment of essential tremor. Mov Disord 25: 1350-1356, 2010

60) Sandvik U, Koskinen LO, Lundquist A, Blomstedt P: Thalamic and subthalamic deep brain stimulation for essential tremor: where is the optimal target? Neurosurgery 70: 840-845; discussion 845-846, 2012

61) Chopra A, Klassen BT, Stead M: Current clinical application of deep-brain stimulation for essential tremor. Neuropsychiatr Dis Treat 9: 1859-1865, 2013
62) Shih LC, LaFaver K, Lim C, Papavassiliou E, Tarsy D: Loss of benefit in VIM thalamic deep brain stimulation (DBS) for essential tremor (ET): how prevalent is it? Parkinsonism Relat Disord 19: 676-679, 2013

63) DiLorenzo DJ, Jankovic J, Simpson RK, Takei H, Powell SZ: Long-term deep brain stimulation for essential tremor: 12-year clinicopathologic follow-up. Mov Disord 25: 232-238, 2010

64) Schlaier J, Anthofer J, Steib K, Fellner C, Rothenfusser E, Brawanski A, Lange M: Deep brain stimulation for essential tremor: targeting the dentato-rubrothalamic tract? Neuromodulation 18: 105-112, 2015

65) Ho AL, Erickson-Direnzo E, Pendharkar AV, Sung CK, Halpern CH: Deep brain stimulation for vocal tremor: a comprehensive, multidisciplinary methodology. Neurosurg Focus 38: E6, 2015

66) Vitek JL: Long-term benefit from deep brain stimulation of the subthalamic nucleus: is it for everyone? Alzheimers Res Ther 4: 13, 2012

67) Tagliati M, Krack P, Volkmann J, Aziz T, Krauss JK, Kupsch A, Vidailhet AM: Long-term management of DBS in dystonia: response to stimulation, adverse events, battery changes, and special considerations. Mov Disord 26(Suppl 1): S54-S62, 2011

68) Starr PA, Bejjani P, Lozano AM, Metman LV, Hariz MI: Stereotactic techniques and perioperative management of DBS in dystonia. Mov Disord 26(Suppl 1): S23-S30, 2011

69) Okun MS, Foote KD: Setting realistic expectations for DBS in dystonia. Lancet Neurol 11: 1014-1015, 2012

70) Jahanshahi M, Czernecki V, Zurowski AM: Neuropsychological, neuropsychiatric, and quality of life issues in DBS for dystonia. Mov Disord 26(Suppl 1): S63-S78, 2011

71) Fox MD, Alterman RL: Brain stimulation for torsion dystonia. JAMA Neurol 72: 713-719, 2015

72) Brüggemann N, Kühn A, Schneider SA, Kamm C, Wolters A, Krause P, Moro E, Steigerwald F, Wittstock M, Tronnier V, Lozano AM, Hamani C, Poon YY, Zittel S, Wächter T, Deuschl G, Krüger R, Kupsch A, Münchau A, Lohmann K, Volkmann J, Klein C: Short- and long-term outcome of chronic pallidal neurostimulation in monogenic isolated dystonia. Neurology 84: 895-903, 2015

73) Haridas A, Tagliati M, Osborn I, Isaias I, Gologorsky Y, Bressman SB, Weisz D, Alterman RL: Pallidal deep brain stimulation for primary dystonia in children. Neurosurgery 68: 738-743; discussion 743, 2011

74) Coubes P, Cif L, El Fertit H, Hemm S, Vayssiere $N$, Serrat S, Picot MC, Tuffery S, Claustres M, Echenne B, Frerebeau P: Electrical stimulation of the globus pallidus internus in patients with primary generalized dystonia: long-term results. J Neurosurg 101: 189-194, 2004

75) Risch V, Staiger A, Ziegler W, Ott K, Scholderle T, Pelykh O, Bötzel K: How does GPi-DBS affect speech in primary dystonia? Brain Stimul 2015 [Epub ahead of print] 
76) Kunieda T, Kikuchi T, Miyamoto S: Epilepsy surgery: surgical aspects. Curr Opin Anaesthesiol 25: 533-539, 2012

77) Kocabicak E, Temel Y, Höllig A, Falkenburger B, Tan SKh: Current perspectives on deep brain stimulation for severe neurological and psychiatric disorders. Neuropsychiatr Dis Treat 11: 1051-1066, 2015

78) Fisher R, Salanova V, Witt T, Worth R, Henry T, Gross R, Oommen K, Osorio I, Nazzaro J, Labar D, Kaplitt M, Sperling M, Sandok E, Neal J, Handforth A, Stern J, DeSalles A, Chung S, Shetter A, Bergen D, Bakay R, Henderson J, French J, Baltuch G, Rosenfeld W, Youkilis A, Marks W, Garcia P, Barbaro N, Fountain N, Bazil C, Goodman R, McKhann G, Babu Krishnamurthy K, Papavassiliou S, Epstein C, Pollard J, Tonder L, Grebin J, Coffey R, Graves N; SANTE Study Group: Electrical stimulation of the anterior nucleus of thalamus for treatment of refractory epilepsy. Epilepsia 51: 899-908, 2010

79) Lee DJ, Zwienenberg-Lee M, Seyal M, Shahlaie K: Intraoperative computed tomography for intracranial electrode implantation surgery in medically refractory epilepsy. J Neurosurg 122: 526-531, 2015

80) Van Gompel JJ, Klassen BT, Worrell GA, Lee KH, Shin C, Zhao CZ, Brown DA, Goerss SJ, Kall BA, Stead M: Anterior nuclear deep brain stimulation guided by concordant hippocampal recording. Neurosurg Focus 38: E9, 2015

81) Hsiao FJ, Yu HY, Chen WT, Kwan SY, Chen C, Yen DJ, Yiu CH, Shih YH, Lin YY: Increased Intrinsic Connectivity of the Default Mode Network in Temporal Lobe Epilepsy: Evidence from Resting-State MEG Recordings. PLoS ONE 10: e0128787, 2015

82) Eryurt B, Oner AY, Ucar M, Capraz I, Kurt G, Bilir E, Tali ET: Presurgical evaluation of mesial temporal lobe epilepsy with multiple advanced MR techniques at 3T. J Neuroradiol 2015 [Epub ahead of print]

83) Chang EF, Englot DJ, Vadera S: Minimally invasive surgical approaches for temporal lobe epilepsy. Epilepsy Behav 47: 24-33, 2015

84) Taylor DC, Marsh SM: Hughlings Jackson's Dr Z: the paradigm of temporal lobe epilepsy revealed. J Neurol Neurosurg Psychiatr 43: 758-767, 1980

85) Fisher RS, Uematsu S, Krauss GL, Cysyk BJ, McPherson R, Lesser RP, Gordon B, Schwerdt P, Rise M: Placebo-controlled pilot study of centromedian thalamic stimulation in treatment of intractable seizures. Epilepsia 33: 841-851, 1992

86) Valentín A, García Navarrete E, Chelvarajah R, Torres C, Navas M, Vico L, Torres N, Pastor J, Selway R, Sola RG, Alarcon G: Deep brain stimulation of the centromedian thalamic nucleus for the treatment of generalized and frontal epilepsies. Epilepsia 54: 1823-1833, 2013

87) Scharf JM, Miller LL, Gauvin CA, Alabiso J, Mathews CA, Ben-Shlomo Y: Population prevalence of Tourette syndrome: a systematic review and meta-analysis. Mov Disord 30: 221-228, 2015

88) Mink JW: Clinical review of DBS for Tourette Syndrome. Front Biosci (Elite Ed) 1: 72-76, 2009
89) Dale RC, Merheb V, Pillai S, Wang D, Cantrill L, Murphy TK, Ben-Pazi H, Varadkar S, Aumann TD, Horne MK, Church AJ, Fath T, Brilot F: Antibodies to surface dopamine-2 receptor in autoimmune movement and psychiatric disorders. Brain 135: 3453-3468, 2012

90) Worbe Y, Malherbe C, Hartmann A, Pélégrini-Issac M, Messé A, Vidailhet M, Lehéricy S, Benali H: Functional immaturity of cortico-basal ganglia networks in Gilles de la Tourette syndrome. Brain 135: 1937-1946, 2012

91) Yasmeen S, Melchior L, Bertelsen B, Skov L, Mol Debes N, Tümer Z: Sequence analysis of SLITRK1 for var321 in Danish patients with Tourette syndrome and review of the literature. Psychiatr Genet 23: 130-133, 2013

92) Schrock LE, Mink JW, Woods DW, Porta M, Servello D, Visser-Vandewalle V, Silburn PA, Foltynie T, Walker HC, Shahed-Jimenez J, Savica R, Klassen BT, Machado AG, Foote KD, Zhang JG, Hu W, Ackermans L, Temel Y, Mari Z, Changizi BK, Lozano A, Auyeung M, Kaido T, Agid Y, Welter ML, Khandhar SM, Mogilner AY, Pourfar MH, Walter BL, Juncos JL, Gross RE, Kuhn J, Leckman JF, Neimat JA, Okun MS; Tourette Syndrome Association International Deep Brain Stimulation (DBS) Database and Registry Study Group: Tourette syndrome deep brain stimulation: a review and updated recommendations. Mov Disord 30: 448-471, 2015

93) Porta M, Servello D, Zanaboni C, Anasetti F, Menghetti C, Sassi M, Robertson MM: Deep brain stimulation for treatment of refractory Tourette syndrome: long-term follow-up. Acta Neurochir (Wien) 154: 2029-2041, 2012

94) Servello D, Sassi M, Brambilla A, Defendi S, Porta M: Long-term, post-deep brain stimulation management of a series of 36 patients affected with refractory gilles de la tourette syndrome. Neuromodulation 13: 187-194, 2010

95) Cannon E, Silburn P, Coyne T, O’Maley K, Crawford JD, Sachdev PS: Deep brain stimulation of anteromedial globus pallidus interna for severe Tourette's syndrome. Am J Psychiatry 169: 860-866, 2012

96) Savica R, Stead M, Mack KJ, Lee KH, Klassen BT: Deep brain stimulation in tourette syndrome: a description of 3 patients with excellent outcome. Mayo Clin Proc 87: 59-62, 2012

97) Smith KM, Spindler MA: Uncommon applications of deep brain stimulation in hyperkinetic movement disorders. Tremor Other Hyperkinet Mov (N Y) 5: 278, 2015

98) Maciunas RJ, Maddux BN, Riley DE, Whitney CM, Schoenberg MR, Ogrocki PJ, Albert JM, Gould DJ: Prospective randomized double-blind trial of bilateral thalamic deep brain stimulation in adults with Tourette syndrome. J Neurosurg 107: 1004-1014, 2007

99) Ackermans L, Duits A, van der Linden C, Tijssen M, Schruers K, Temel Y, Kleijer M, Nederveen P, Bruggeman R, Tromp S, van Kranen-Mastenbroek V, Kingma H, Cath D, Visser-Vandewalle V: Doubleblind clinical trial of thalamic stimulation in patients with Tourette syndrome. Brain 134: 832-844, 2011 
100) Okun MS, Foote KD, Wu SS, Ward HE, Bowers D, Rodriguez RL, Malaty IA, Goodman WK, Gilbert DM, Walker HC, Mink JW, Merritt S, Morishita T, Sanchez JC: A trial of scheduled deep brain stimulation for Tourette syndrome: moving away from continuous deep brain stimulation paradigms. JAMA Neurol 70: 85-94, 2013

101) Müller-Vahl KR: Surgical treatment of Tourette syndrome. Neurosci Biobehav Rev 37: 1178-1185, 2013

102) Velasco AL, Velasco F, Jiménez F, Velasco $M$, Castro G, Carrillo-Ruiz JD, Fanghänel G, Boleaga B: Neuromodulation of the centromedian thalamic nuclei in the treatment of generalized seizures and the improvement of the quality of life in patients with Lennox-Gastaut syndrome. Epilepsia 47: 1203-1212, 2006

103) Viswanathan A, Jimenez-Shahed J, Baizabal Carvallo JF, Jankovic J: Deep brain stimulation for Tourette syndrome: target selection. Stereotact Funct Neurosurg 90: 213-224, 2012

104) Okumura Y, Higuchi T: Cost of depression among adults in Japan. Prim Care Companion CNS Disord 13: pii, 2011

105) Wang PS, Lane M, Olfson M, Pincus HA, Wells KB, Kessler RC: Twelve-month use of mental health services in the United States: results from the National Comorbidity Survey Replication. Arch Gen Psychiatry 62: 629-640, 2005

106) Schlaepfer TE, Bewernick BH: Deep brain stimulation for major depression. Handbook Clin Neurol 116: 235-243, 2013

107) Merkl A, Schneider GH, Schönecker T, Aust S, Kühl KP, Kupsch A, Kühn AA, Bajbouj M: Antidepressant effects after short-term and chronic stimulation of the subgenual cingulate gyrus in treatment-resistant depression. Exp Neurol 249: 160-168, 2013

108) Holtzheimer PE, Kelley ME, Gross RE, Filkowski MM, Garlow SJ, Barrocas A, Wint D, Craighead MC, Kozarsky J, Chismar R, Moreines JL, Mewes K, Posse PR, Gutman DA, Mayberg HS: Subcallosal cingulate deep brain stimulation for treatmentresistant unipolar and bipolar depression. Arch Gen Psychiatry 69: 150-158, 2012

109) Awan NR, Lozano A, Hamani C: Deep brain stimulation: current and future perspectives. Neurosurg Focus 27: E2, 2009

110) Mayberg HS, Lozano AM, Voon V, McNeely HE, Seminowicz D, Hamani C, Schwalb JM, Kennedy SH: Deep brain stimulation for treatment-resistant depression. Neuron 45: 651-660, 2005

111) Grubert C, Hurlemann R, Bewernick BH, Kayser S, Hadrysiewicz B, Axmacher N, Sturm V, Schlaepfer TE: Neuropsychological safety of nucleus accumbens deep brain stimulation for major depression: effects of 12-month stimulation. World J Biol Psychiatry 12: 516-527, 2011

112) Dougherty DD, Rezai AR, Carpenter LL, Howland RH, Bhati MT, O’Reardon JP, Eskandar EN, Baltuch
GH, Machado AD, Kondziolka D, Cusin C, Evans KC, Price LH, Jacobs K, Pandya M, Denko T, Tyrka AR, Brelje T, Deckersbach T, Kubu C, Malone DA Jr: A randomized sham-controlled trial of deep brain stimulation of the ventral capsule/ventral striatum for chronic treatmentresistant depression. Biol Psychiatry 78: 240-248, 2015

113) Mavridis IN: Deep brain stimulation for psychiatric disorders: are nucleus accumbens and medial forebrain bundle two branches of the same tree? Neurosci Biobehav Rev pii: S0149-S7634(15)00089-5, 2015

114) Luigjes J, van den Brink W, Feenstra M, van den Munckhof P, Schuurman PR, Schippers R, Mazaheri A, De Vries TJ, Denys D: Deep brain stimulation in addiction: a review of potential brain targets. Mol Psychiatry 17: 572-583, 2012

115) Hall W, Carter A: Is deep brain stimulation a prospective "cure" for addiction? F1000 Med Rep 3: 4, 2011

116) Halpern CH, Torres N, Hurtig HI, Wolf JA, Stephen J, Oh MY, Williams NN, Dichter MA, Jaggi JL, Caplan AL, Kampman KM, Wadden TA, Whiting DM, Baltuch GH: Expanding applications of deep brain stimulation: a potential therapeutic role in obesity and addiction management. Acta Neurochir (Wien) 153: 2293-2306, 2011

117) Kuhn J, Lenartz D, Huff W, Lee S, Koulousakis A, Klosterkoetter J, Sturm V: Remission of alcohol dependency following deep brain stimulation of the nucleus accumbens: valuable therapeutic implications? J Neurol Neurosurg Psychiatr 78: 1152-1153, 2007

118) Müller UJ, Sturm V, Voges J, Heinze HJ, Galazky I, Heldmann M, Scheich H, Bogerts B: Successful treatment of chronic resistant alcoholism by deep brain stimulation of nucleus accumbens: first experience with three cases. Pharmacopsychiatry 42: 288-291, 2009

119) Kuhn J, Moller M, Treppmann JF, Bartsch C, Lenartz D, Gruendler TO, Maarouf M, Brosig A, Barnikol UB, Klosterkotter J, Sturm V: Deep brain stimulation of the nucleus accumbens and its usefulness in severe opioid addiction. Mol Psychiatry 19: 145-146, 2014

120) Voges J, Müller U, Bogerts B, Münte T, Heinze HJ: Deep brain stimulation surgery for alcohol addiction. World Neurosurg 80: S28 e21-31, 2013

121) Creed M, Pascoli VJ, Lüscher C: Addiction therapy. Refining deep brain stimulation to emulate optogenetic treatment of synaptic pathology. Science 347: 659-664, 2015

122) Murray CJ, Lopez AD: Measuring the global burden of disease. N Engl J Med 369: 448-457, 2013

123) Joshi GP, Ahmad S, Riad W, Eckert S, Chung F: Selection of obese patients undergoing ambulatory surgery: a systematic review of the literature. Anesth Analg 117: 1082-1091, 2013 
124) Pisapia JM, Halpern CH, Williams NN, Wadden TA, Baltuch GH, Stein SC: Deep brain stimulation compared with bariatric surgery for the treatment of morbid obesity: a decision analysis study. Neurosurg Focus 29: E15, 2010

125) Halpern CH, Wolf JA, Bale TL, Stunkard AJ, Danish SF, Grossman M, Jaggi JL, Grady MS, Baltuch GH: Deep brain stimulation in the treatment of obesity. J Neurosurg 109: 625-634, 2008

126) Ho AL, Sussman ES, Pendharkar AV, Azagury DE, Bohon C, Halpern CH: Deep brain stimulation for obesity: rationale and approach to trial design. Neurosurg Focus 38: E8, 2015

127) Melega WP, Lacan G, Gorgulho AA, Behnke EJ, De Salles AA: Hypothalamic deep brain stimulation reduces weight gain in an obesity-animal model. PLoS ONE 7: e30672, 2012

128) Hamani C, McAndrews MP, Cohn M, Oh M, Zumsteg D, Shapiro CM, Wennberg RA, Lozano AM: Memory enhancement induced by hypothalamic/ fornix deep brain stimulation. Ann Neurol 63: 119-123, 2008

129) Jennings JH, Rizzi G, Stamatakis AM, Ung RL, Stuber GD: The inhibitory circuit architecture of the lateral hypothalamus orchestrates feeding. Science 341: 1517-1521, 2013

130) Whiting DM, Tomycz ND, Bailes J, de Jonge L, Lecoultre V, Wilent B, Alcindor D, Prostko ER, Cheng BC, Angle C, Cantella D, Whiting BB, Mizes JS, Finnis KW, Ravussin E, Oh MY: Lateral hypothalamic area deep brain stimulation for refractory obesity: a pilot study with preliminary data on safety, body weight, and energy metabolism. J Neurosurg 119: 56-63, 2013

131) Dong Q, Wang $Y, G u$ P, Shao R, Zhao L, Liu X, Wang Z, Wang M: The neuroprotective mechanism of low-frequency rTMS on nigral dopaminergic neurons of Parkinson's disease model mice. Parkinsons Dis 2015: 564095, 2015

132) Gut NK, Winn P: Deep brain stimulation of different pedunculopontine targets in a novel rodent model of parkinsonism. J Neurosci 35: 4792-4803, 2015

133) Zimnik AJ, Nora GJ, Desmurget M, Turner RS: Movement-related discharge in the macaque globus pallidus during high-frequency stimulation of the subthalamic nucleus. J Neurosci 35: 3978-3989, 2015

134) Santana MB, Halje $P$, Simplício $H$, Richter $U$, Freire MA, Petersson P, Fuentes R, Nicolelis MA: Spinal cord stimulation alleviates motor deficits in a primate model of Parkinson disease. Neuron 84: 716-722, 2014

135) Lei X, Huang B, Li H, Jiang H, Hu X, Zhang B: Drift in centrality of different brain regions in an anatomical neural network with Parkinson's disease: a view from complex network analysis. Neuroscience 299: 107-124, 2015

136) Prabhu S, Chabardès S, Sherdil A, Devergnas A, Michallat S, Bhattacharjee M, Mathieu H, David O,
Piallat B: Effect of subthalamic nucleus stimulation on penicillin induced focal motor seizures in primate. Brain Stimul 8: 177-184, 2015

137) Lipski WJ, DeStefino VJ, Stanslaski SR, Antony AR, Crammond DJ, Cameron JL, Richardson RM: Sensing-enabled hippocampal deep brain stimulation in idiopathic nonhuman primate epilepsy. J Neurophysiol 113: 1051-1062, 2015

138) Cheng JJ, Anderson WS: Closed-loop deep brain stimulation successfully modulates hippocampal activity in an animal model. Neurosurgery 76: N13-N15, 2015

139) de Oliveira JC, Medeiros Dde C, de Souza E Rezende GH, Moraes MF, Cota VR: Temporally unstructured electrical stimulation to the amygdala suppresses behavioral chronic seizures of the pilocarpine animal model. Epilepsy Behav 36: 159-164, 2014

140) Rouaud T, Lardeux S, Panayotis N, Paleressompoulle D, Cador M, Baunez C: Reducing the desire for cocaine with subthalamic nucleus deep brain stimulation. Proc Natl Acad Sci USA 107: 11961200, 2010

141) Guercio LA, Schmidt HD, Pierce RC: Deep brain stimulation of the nucleus accumbens shell attenuates cue-induced reinstatement of both cocaine and sucrose seeking in rats. Behav Brain Res 281: 125-130, 2015

142) Hamilton J, Lee J, Canales JJ: Chronic unilateral stimulation of the nucleus accumbens at high or low frequencies attenuates relapse to cocaine seeking in an animal model. Brain Stimul 8: 57-63, 2015

143) Worbe Y, Sgambato-Faure V, Epinat J, Chaigneau M, Tandé D, François C, Féger J, Tremblay L: Towards a primate model of Gilles de la Tourette syndrome: anatomo-behavioural correlation of disorders induced by striatal dysfunction. Cortex 49: 1126-1140, 2013

144) Rea E, Rummel J, Schmidt TT, Hadar R, Heinz A, Mathé AA, Winter C: Anti-anhedonic effect of deep brain stimulation of the prefrontal cortex and the dopaminergic reward system in a genetic rat model of depression: an intracranial self-stimulation paradigm study. Brain Stimul 7: 21-28, 2014

145) Lim LW, Prickaerts J, Huguet G, Kadar E, Hartung H, Sharp T, Temel Y: Electrical stimulation alleviates depressive-like behaviors of rats: investigation of brain targets and potential mechanisms. Transl Psychiatry 5: e535, 2015

146) Cooperrider J, Furmaga H, Plow E, Park HJ, Chen Z, Kidd G, Baker KB, Gale JT, Machado AG: Chronic deep cerebellar stimulation promotes longterm potentiation, microstructural plasticity, and reorganization of perilesional cortical representation in a rodent model. J Neurosci 34: 9040-9050, 2014

147) Rodriguez-Romaguera J, Do Monte FH, Quirk GJ: Deep brain stimulation of the ventral striatum 
enhances extinction of conditioned fear. Proc Natl Acad Sci USA 109: 8764-8769, 2012

148) Kim J, Lee SE, Shin J, Jung HH, Kim SJ, Chang JW: The neuromodulation of neuropathic pain by measuring pain response rate and pain response duration in animal. J Korean Neurosurg Soc 57: 6-11, 2015

149) Tabansky I, Quinkert AW, Rahman N, Muller SZ, Lofgren J, Rudling J, Goodman A, Wang Y, Pfaff DW: Temporally-patterned deep brain stimulation in a mouse model of multiple traumatic brain injury. Behav Brain Res 273: 123-132, 2014

150) Lane E: Neuroscience. Will brain stimulation technology lead to "neuroenhancement"? Science 342: 438, 2013
151) Ling G: Newsmaker interview: Geoffrey Ling. DARPA aims to rebuild brains. Interview by Emily Underwood. Science 342: 1029-1030, 2013

152) Ozbay BN, Losacco JT, Cormack R, Weir R, Bright VM, Gopinath JT, Restrepo D, Gibson EA: Miniaturized fiber-coupled confocal fluorescence microscope with an electrowetting variable focus lens using no moving parts. Optics Lett 40: 2553-2556, 2015

Address reprint requests to: Anand Tekriwal, MD, PhD, Candidate at the University of Colorado Anschutz School of Medicine, Colorado, USA. e-mail: tekriwal@sas.upenn.edu 